\title{
Qualidade Ambiental da Bacia Hidrográfica do Córrego Oriente em Adamantina/SP
}

Environmental Quality of the Orient Stream River Hydrographic Basin in Adamantina/SP

Calidad Ambiental de la Cuenca Hidrográfica del Córrego Oriente en Adamantina/SP

Alan Lima dos Reis

Engenheiro Ambiental, UNIFAl, Brasil. al.reis2012@hotmail.com

José Aparecido dos Santos Professor Doutor, UNIFAI, Brasil. cido@fai.com.br

Denilson Burkert Pesquisador Doutor, APTA Regional, Brasil. denilsonb@apta.sp.gov.br 


\section{RESUMO}

O acesso a água potável tornou-se uma questão estratégica e o Estado mais populoso do país almeja alcançar o pleno desenvolvimento socioeconômico para superar os seus desafios socioambientais. Para tanto, foi utilizado técnicas de Geoprocessamento para analisar o alto curso da bacia hidrográfica do córrego do Oriente localizado no município de Adamantina - SP. Logo, o objetivo foi realizar um levantamento sobre o uso do solo e os seus efeitos sobre a qualidade da água na bacia hidrográfica. Os resultados apontam para um forte predomínio de pastagens, variação de zero a oito graus de declividade ao longo da área e uma diferença de altitude da cota de 350 metros para a cota de 500 metros. Juntamente, destaca-se a falta de vegetação, assoreamento do curso do rio e a presença de erosões. Quanto as análises de água realizadas nos meses de maio e agosto, apenas o Oxigênio Dissolvido e a Demanda Bioquímica de Oxigênio apresentaram valores significativos de alteração de acordo com a resolução CONAMA no 357/2005, que dispõe os valores máximos permitidos para este córrego de classe 2 . Assim, políticas e gestão do uso e ocupação do solo desta bacia hidrográfica necessitam de reformulações, principalmente para manter a segurança hídrica da presente e futuras gerações.

PALAVRAS-CHAVE: Bacia Hidrográfica. Geoprocessamento. Qualidade Ambiental.

\section{ABSTRACT}

Access to clean drinking water become a strategic issue and the country's most populous State aims to accomplish the absolute socioeconomic development to overcome their environmental challenges. In order to it's used to geoprocessing techniques to analyze the Orient Stream River Hydrographic Basin in Adamantina - SP. Therefore the purpose of this study was to carry a survey about the use of soil and their effects to the quality of the water in the hydrological basin. The results indicate to a strong predominance of pastures, variation from zero to eight degrees to declivity along the area and a difference at an altitude quote of 350 meters to 500 meters. Along with it highlights the lack of vegetation, the sedimentation the river course and the presence of erosion. With the respect to water analyses accomplished in May and August, only Dissolved Oxygen and of the Biochemical Oxygen Demand shown significant increases of values changed in accordance with CONAMA Resolution No 357/2005, in which establishes the maximum permissible values for this class stream 2. Accordingly, policies and management occupation and of land use to this hydrographic basin require some reformulations, mainly to maintain the water safety of present and future generations.

KEYWORDS: Hydrographic Basin. Geoprocessing. Environmental Quality.

\section{RESUMEN}

El acceso al agua potable se ha convertido en una cuestión estratégica y el Estado más poblado del país desea alcanzar el pleno desarrollo socioeconómico para superar sus desafíos socioambientales. Para ello, se utilizaron técnicas de Geoprocesamiento para analizar el alto curso de la cuenca hidrográfica del arroyo de Oriente ubicado en el municipio de Adamantina - SP. Luego, el objetivo fue realizar un levantamiento sobre el uso del suelo y sus efectos sobre la calidad del agua en la cuenca hidrográfica. Los resultados apuntan a un fuerte predominio de pastos, variación de cero a ocho grados de declividad a lo largo del área y una diferencia de altitud de la cuota de 350 metros a la cuota de 500 metros. En conjunto, se destaca la falta de vegetación, la sedimentación del curso del río y la presencia de erosiones. En cuanto a los análisis de agua realizados en los meses de mayo y agosto, sólo el Oxígeno disuelto y la Demanda Bioquímica de Oxígeno presentaron valores significativos de alteración de acuerdo con la resolución CONAMA no 357/2005, que dispone los valores máximos permitidos para este arroyo de clase 2 . Así, las políticas y la gestión del uso y ocupación del suelo de esta cuenca hidrográfica necesitan reformulaciones, principalmente para mantener la seguridad hídrica de la presente y futuras generaciones.

PALABRAS-CLAVE: Cuenca Hidrográfica. Geoprocesamiento. Calidad Del Medio Ambiente. 


\section{INTRODUÇÃO}

A partir da Política Nacional de Recursos Hídricos (PNRH) gerada e fundamentada pela lei no 9.433/1997 estabelece-se que a água é um recurso natural limitado, de domínio público, e dotado de valor econômico. Além disso, a PNRH indicou a bacia hidrográfica como unidade territorial para sua implementação. Segundo SILVA et al., (2015) a bacia hidrográfica pode ser considerada como a unidade de controle para as entradas e saídas de fluxos contínuos de materiais, sendo a sua delimitação uma ferramenta essencial no planejamento e gerenciamento dos recursos disponíveis. Na adoção desta unidade fundamental está implícita uma visão sistêmica e integrada do ambiente, sendo assim, essenciais para a sua gestão o conhecimento e avaliação dos diversos componentes, processos e interações que nela ocorrem (GUERRA; CUNHA, 2007). MENEZES et al., (2009) atribuem que a degradação ambiental de uma determinada bacia hidrográfica está relacionada com o uso e ocupação do seu solo. O processo de ocupação desordenada do solo agrava os desequilíbrios e acelera as transformações paisagísticas, diminuindo a retenção de água e elevando a taxa de degradação do solo (SILVA, 2014). A sequência do desenvolvimento social e econômico tem reflexos diretos sobre a qualidade ambiental nas bacias hidrográficas, VANZELA et al., (2010) elencam diretamente o uso e a ocupação do solo atuando na influência do escoamento superficial e aporte de sedimentos no leito dos mananciais, podendo acarretar alteração da qualidade e disponibilidade de água ao longo dos anos. XAVIER, (2005) avaliando a influência do uso e ocupação do solo sobre a qualidade de água, apontou que mudanças ocasionadas na natureza e nas atividades antrópicas se relacionam tanto no aumento da demanda quanto na poluição da água. Estes efeitos negativos ocasionados pela atividade antrópica ao meio ambiente por meio do uso inadequado do solo, acabam prejudicando os serviços ecossistêmicos essenciais ARAÚJO et al., (2015). Dessa maneira, os impactos gerados pelo uso e ocupação do solo realizado de forma descontrolada produzem, por consequência, efeitos deletérios à qualidade da água (CUNHA et al., 2016; Menezes et al., 2016). O Estado de São Paulo está dividido em 22 Unidades Hidrográficas de Gerenciamento de Recursos Hídricos (UGRHI). O município de Adamantina se encontra dividido entre as UGRHIs 20 (rio Aguapeí/Feio) e 21 (rio do Peixe). A bacia hidrográfica do córrego Oriente é situada no município de Adamantina e está inserida na região médio da bacia do rio Aguapeí/Feio. Ela ocupa a porção centro oeste da área urbana envolvendo o Distrito Industrial, faz divisa com a bacia do córrego da Esperança e do córrego Lambari (Figura 1 e Figura 2). 0 córrego detém algumas de suas principais nascentes na área urbana do município e outras em área rural, com trechos de seu fundo de vale bastante degradados pela ação do assoreamento e o desencadeamento das erosões. Na bacia do córrego Oriente são encontradas erosões hídricas em vertentes muito longas suscetíveis a ocorrência destes fenômenos (IPT, 2009). O solo predominante é do tipo Argissolos abrúpticos, um relevo suave a ondulado, formado por colinas médias. A classificação climática de Köppen é do tipo Cwa, caracterizado pelo clima tropical de altitude com chuvas no verão e seca no inverno. 
Analisar a qualidade ambiental da bacia do córrego Oriente a partir da geração de mapas temáticos sobre o uso do solo e identificar suas relações com parâmetros de qualidade de água.

\section{MÉTODO DE ANÁLISE}

\subsection{Imagens utilizadas}

Os mapas de declividade e hipsometria foram confeccionados a partir da imagem digital altimétrica do Estado de São Paulo com resolução de 90 metros, formato GEOTIFF, Datum WGS-84, disponibilizada gratuitamente pelo site da Empresa Brasileira de Pesquisa Agropecuária (EMBRAPA) divisão de monitoramento por satélite, adquirida pela missão Shuttle Radar Topography Mission - (SRTM), conduzida pela National Aeronautics and Space Administration (NASA) em parceria com Agenzia Spaziale Italiana (ASI) e Deutsches Zentrum für Luft-und Raumfahrt (DLR). Foi produzido o mapa de uso e ocupação do solo utilizando a imagem digital Thematic Mapper (TM) do satélite Landsat 5 datada de 16-08-2011, órbita 222, ponto 75, formato GEOTIFF, disponibilizada pelo Instituto Nacional de Pesquisas Espaciais (INPE).

\subsection{Sistemas utilizados}

Os mapas temáticos de (uso e ocupação do solo, declividade e hipsometria) foram elaborados com a utilização do software SPRING. Após o tratamento da imagem (TM) de 2011 foi delimitada a área de estudo, criando assim, as classes de uso e ocupação do solo predominantes na bacia, como: (cana de açúcar, limite da bacia, pastagens, rede hidrográfica, silvicultura, urbanização e vegetação). Os polígonos estabelecidos foram calibrados e identificados de acordo com a característica de cada classe constituída. Por final, foi gerado o cálculo de cada classe predominante em hectares (ha) para o mapa de uso e ocupação do solo. As cartas de declividade e de hipsometria foram elaboradas utilizando a imagem digital (SRTM), o software reconhece a altimetria e expressou as informações de acordo com a região de estudo. O software GOOGLE EARTH foi aplicado para a delimitação da área de estudo e utilização do acervo de imagens de alta resolução para comparação com a imagem (TM) de 2011.

\subsection{Coleta e análise de água}

A coleta e análise de água do Córrego Oriente ocorreu em pontos distintos, à montante do córrego (ponto 1) e à jusante do córrego (ponto 2) nos meses de maio e agosto de 2015 (Figura 3). O primeiro ponto é situado na passagem do rio por uma ponte construída na estrada rural, o segundo ponto fica próximo à Estação de Tratamento de Esgoto (ETE) da Companhia de Saneamento Básico do Estado de São Paulo (SABESP) que deságua o efluente no córrego Lambari.

Figura 3: Pontos de coleta de água na bacia do córrego Oriente Adamantina/SP 


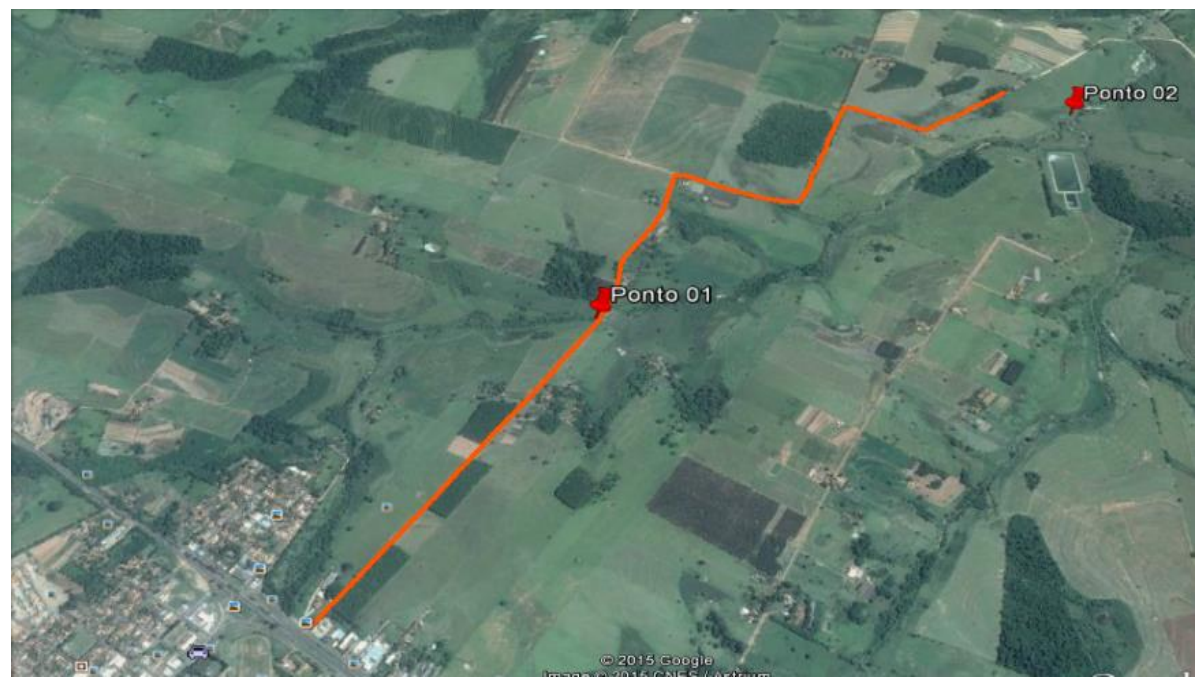

Fonte: GOOGLE EARTH, 2015.

Para a avaliação da qualidade de água foi utilizado o analisador multiparâmetro Hanna 9828. A sua sonda foi inserida dentro dos corpos d'água in loco permitindo a determinação dos parâmetros Condutividade Elétrica; Concentração de Oxigênio Dissolvido; pH; Salinidade, Sólidos Suspensos Ttotais; Temperatura. A seguir, foram colhidas amostras de água em garrafas plásticas de 1 l e encaminhadas ao Laboratório de Qualidade de Água do Centro Universitário de Adamantina (UNIFAI). A partir delas, foram determinados Demanda Bioquímica de Oxigênio - $\mathrm{DBO}_{5}{ }^{20}$, para isso, as amostras ficaram incubadas por um período de 5 dias a uma temperatura constante de 20 ․ C. Foi também determinada turbidez da água utilizando o turbidímetro Hanna HI 93703. Segundo a resolução CONAMA no 357/2005 as águas do córrego Oriente são de classe 2 conforme enquadramento dos corpos de água pelo Decreto no 10755/1977 do Estado de São Paulo. Sendo assim, os valores dos parâmetros de qualidade de água obtidos a partir das coletas foram comparados com os valores descritos em sua classificação.

\subsection{Averiguação dos danos ambientais}

Para a análise dos danos ambientais foi utilizado o Plano de Macrodrenagem de Adamantina SP, parecer técnico no 15713-301-1 realizado pelo Instituto de Pesquisas Tecnológicas (IPT) no ano de 2009, no qual, foram identificados locais com a presença de erosões e drenagens deficitárias.

\section{RESULTADOS}

A partir do mapa de uso e ocupação do solo pode se observar que no ano de 2011 (Tabela 1) a bacia apresentava um predomínio de pastagens, totalizando aproximadamente 469,98ha, correspondendo a $58,90 \%$ da área total.

A urbanização assumiu 170,37ha, representando $21,35 \%$. Ao longo do curso d'água, foram detectados locais com a presença e ausência de vegetação (Figura 4), no entanto, equivalem a 84,87 ha correspondendo a 10,64\%. O cultivo de cana de açúcar assumiu 6,56\% da área total, o que representou um total de $52,38 \mathrm{ha}$. A silvicultura, cultivo de seringueira e principalmente 
eucalipto, demonstrou uma área de cultivo de 19,35ha correspondendo a 2,42\%. As lagoas que foram encontradas no mapeamento foram classificadas como pontos de água.

Tabela 1: Classes e porcentagens do uso e ocupação do solo na bacia do córrego Oriente Adamantina/SP

\begin{tabular}{|lcc|}
\hline Classes & Área em Hectares (ha) & Porcentagens \\
\hline Pastagens & 469,98 & $58,90 \%$ \\
\hline Urbanização & 170,37 & $21,35 \%$ \\
\hline Vegetação & 84,87 & $10,64 \%$ \\
\hline Cana de açúcar & 52,38 & $6,56 \%$ \\
\hline Silvicultura & 19,35 & $2,42 \%$ \\
\hline Pontos de água & 0,99 & $0,12 \%$ \\
\hline Área total & $\mathbf{7 9 7 , 9 4}$ & $\mathbf{1 0 0 , 0 0 \%}$ \\
\hline
\end{tabular}

Figura 4: Carta de uso e ocupação do solo da bacia do córrego Adamantina/SP

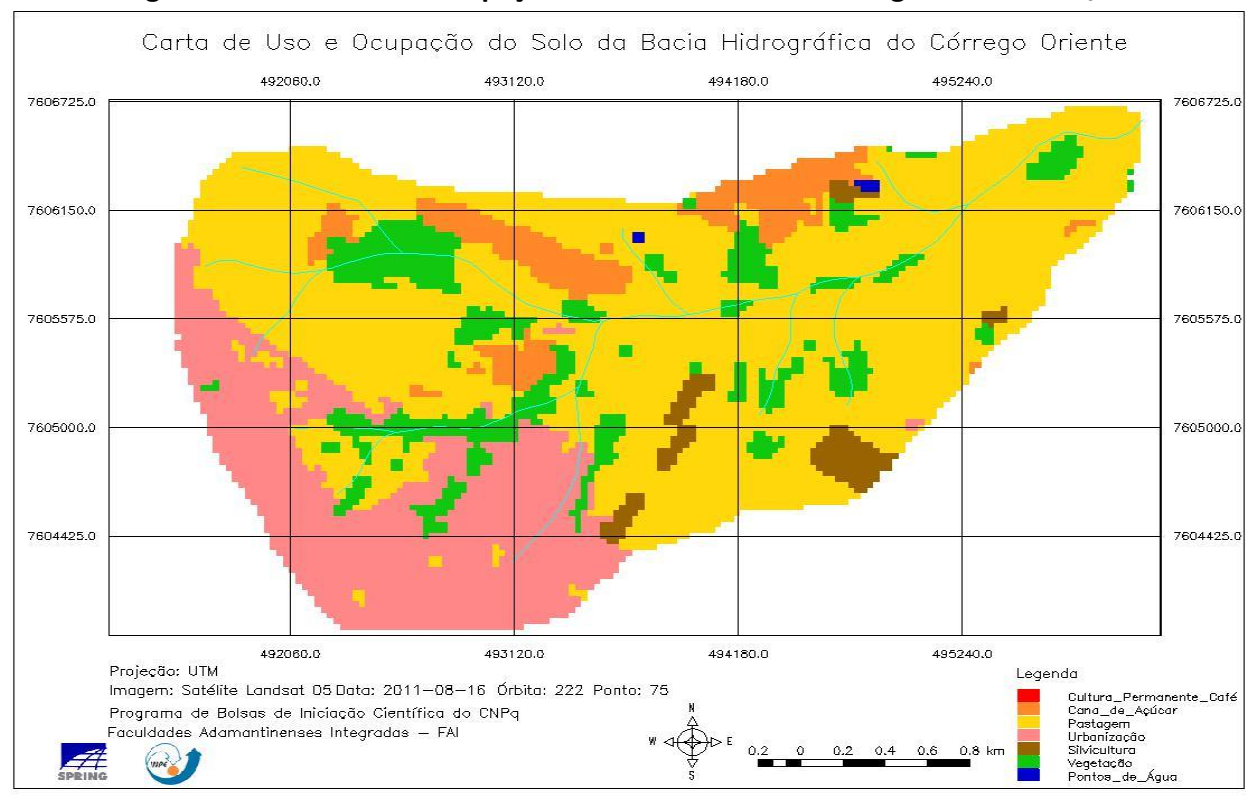

A área da bacia hidrográfica apresentou uma variação de zero a oito graus de declividade ao longo do trecho (Figura 5). Quanto à elevação, houve uma variação de altitude da cota de 350 metros para a cota de 500 metros (Figura 6). A declividade de uma bacia hidrográfica se relaciona com o aumento da velocidade do escoamento superficial, no qual colabora para o agravamento principalmente dos fenômenos de erosão e assoreamento quando um solo se encontra desprotegido de cobertura vegetal (SETTI et al., 2001). 
Figura 5: Carta de declividade da bacia do córrego Oriente Adamantina/SP

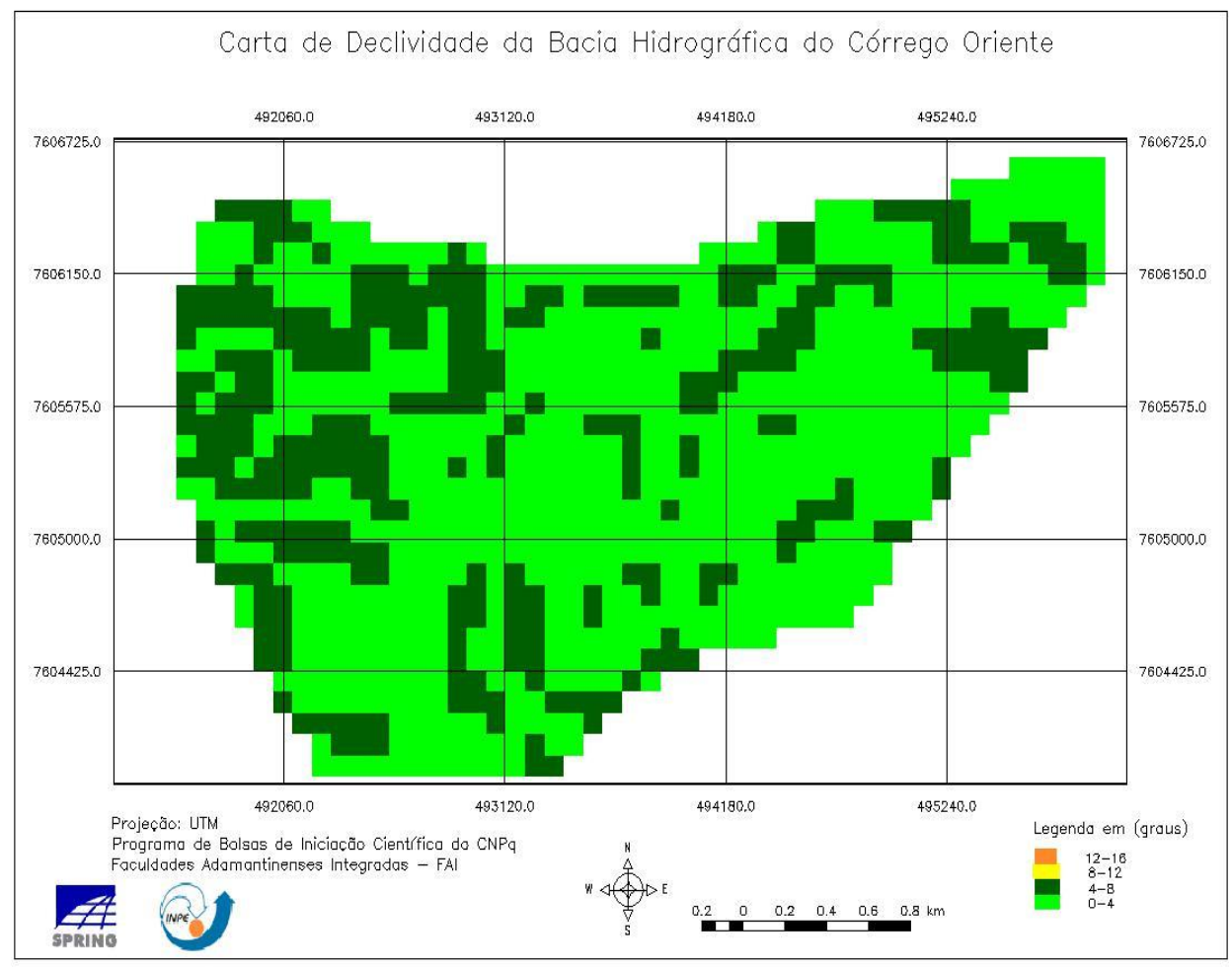

Figura 6: Carta de hipsometria da bacia do córrego Oriente Adamantina/SP

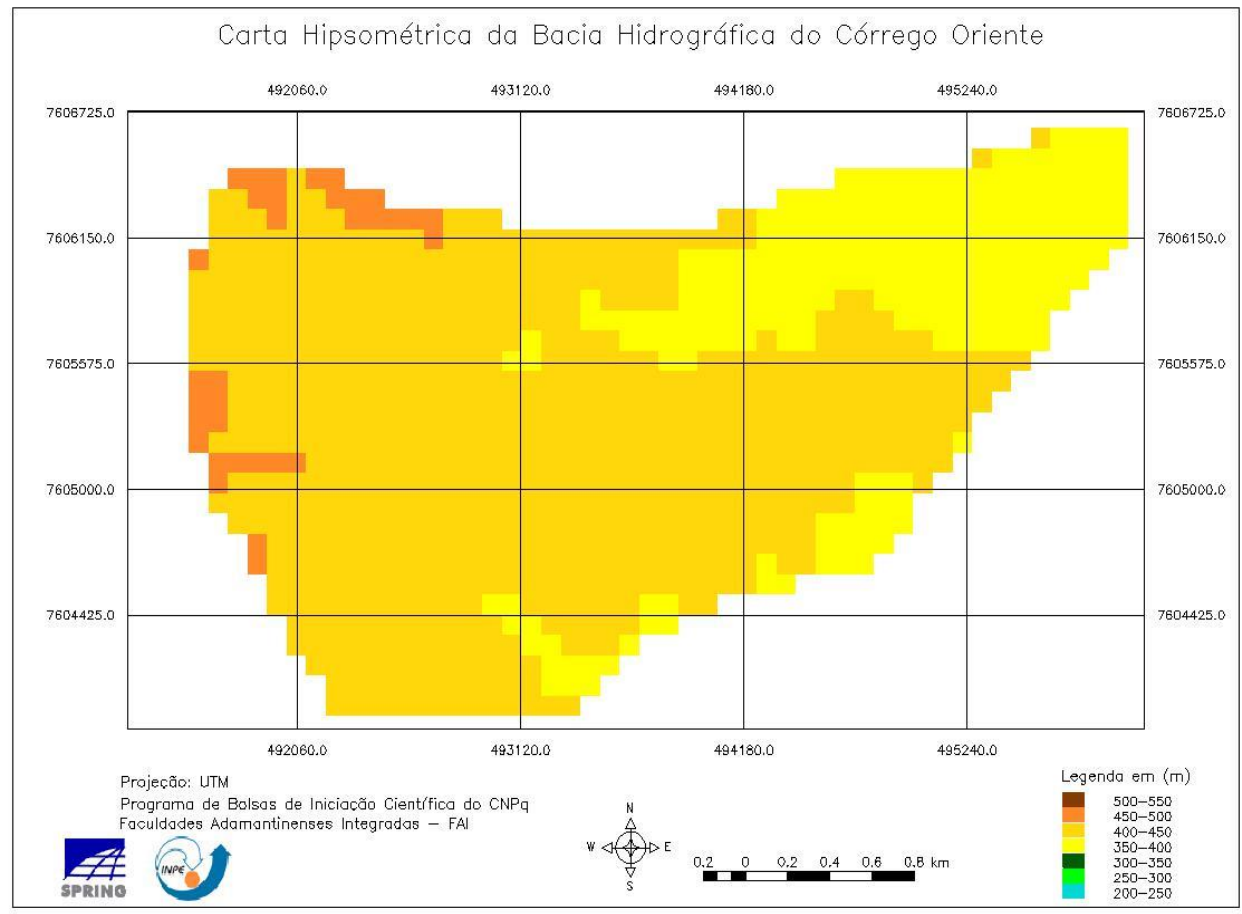

\subsection{Análise de água}

Em relação à resolução CONAMA no 357/2005, puderam ser observadas alterações significativas apenas para os parâmetros de $\mathrm{DBO}_{5}{ }^{20}$ a qual apresentou para o primeiro ponto o 
valor de $11 \mathrm{mg} / \mathrm{l}$ e $14 \mathrm{mg} / \mathrm{l}$ para o segundo ponto, ambos no mês de maio. Já nas análises do mês de agosto, foram registrados $6 \mathrm{mg} / \mathrm{l}$ e $8 \mathrm{mg} / \mathrm{l}$ para o primeiro e segundo ponto respectivamente. Para a concentração de oxigênio dissolvido os valores foram de $3,57 \mathrm{mg} / \mathrm{l}$ para o segundo ponto (Tabela 2).

Tabela 2: Resultado das análises de água na bacia do córrego Oriente Adamantina/SP

\begin{tabular}{|c|c|c|c|c|}
\hline \multirow{3}{*}{$\begin{array}{c}\text { Tipo: Água Doce } \\
\text { Parâmetros }\end{array}$} & \multicolumn{2}{|c|}{ Ambiente: Lótico } & \multicolumn{2}{|c|}{ Classe: 2} \\
\hline & \multicolumn{2}{|c|}{ Análise maio / 2015} & \multicolumn{2}{|c|}{ Análise agosto / 2015} \\
\hline & Ponto 01 & Ponto 02 & Ponto 01 & Ponto 02 \\
\hline $\mathrm{pH}$ & 7,75 & 7,94 & 7,50 & 7,65 \\
\hline $\mathrm{pHmV}$ & $-42,06$ & $-51,43$ & $-13,23$ & $-21,40$ \\
\hline oC & 26,33 & 27,70 & 22,23 & 23,01 \\
\hline mbar & 982,96 & 986,43 & 986,0 & 987,0 \\
\hline $\mathrm{mS} / \mathrm{cm}$ & 0,341 & 0,464 & 0,280 & 0,514 \\
\hline$\mu \mathrm{S} / \mathrm{cm}^{2}$ & 350 & 488 & 271 & 494 \\
\hline tdsppm & 171 & 232 & 143 & 257 \\
\hline Salinidade & 0,16 & 0,22 & 0,14 & 0,25 \\
\hline D.O \% & 95,43 & 83,90 & 62,96 & 42,70 \\
\hline D.O. $(\mathrm{mg} / \mathrm{l})$ & 7,29 & 6,60 & 5,36 & 3,57 \\
\hline Turbidez UNT & 8,76 & 13,17 & 20,22 & 21,80 \\
\hline $\mathrm{DBO}_{5}{ }^{20} \mathrm{mg} / \mathrm{l}$ & 11 & 14 & 6 & 8 \\
\hline
\end{tabular}

Valores Máximos Permitidos - Conama no 357/2005: pH entre 6 a 9; Salinidade igual ou inferior a 0,5; Oxigênio Dissolvido não inferior a $5 \mathrm{mg} / \mathrm{l}$; Turbidez até 100 UNT; DBO $_{5}{ }^{20}$ até $5 \mathrm{mg} / \mathrm{l}$.

De acordo com essas informações e juntamente com a resolução CONAMA no 357/2005 as águas do córrego podem ser utilizadas para: abastecimento público após tratamento convencional; proteção das comunidades aquáticas; recreação de contato primário; irrigação de hortaliças, plantas frutíferas e de parques, jardins, campos de esporte e lazer; aquicultura e atividade de pesca.

\subsection{Discussão}

No ano de 2011 a bacia do córrego Oriente apresentou um predomínio de pastagens e uma variação de zero a oito graus de declividade ao longo da área. Esta relação agrava a formação de erosões e o assoreamento do córrego, o escoamento superficial ganha velocidade causando então o surgimento dos fenômenos, já que os locais se encontram desprotegidos de cobertura vegetal. Foram identificados diversos danos ambientais na bacia, destacando-se a falta de vegetação nas áreas de nascentes do córrego; o assoreamento do curso do rio; a presença de erosões com a devida localização e surgimento (Quadro 1).

Quadro 1: Erosões analisadas na bacia do córrego Oriente Adamantina/SP

\begin{tabular}{|l|l|}
\hline \multicolumn{1}{|c|}{ Localização } & \multicolumn{1}{c|}{ Causa/Surgimento } \\
\hline $\begin{array}{l}\text { 1) Altura do km 594, rodovia Comandante João Ribeiro } \\
\text { de Barros SP-294 próximo ao trevo de acesso ao campus }\end{array}$ & -Drenagem deficitária do local (IPT, 2009). \\
II do Centro Universitário de Adamantina (UNIFAI). & \\
\hline $\begin{array}{l}\text { 2) Rodovia Comandante João Ribeiro de Barros SP-294 } \\
\text { próximo ao trevo com destino ao bairro Lagoa Seca e }\end{array}$ & -Drenagem deficitária do local (IPT, 2009). \\
\hline
\end{tabular}


município de Valparaíso/SP.

Expansão dos núcleos habitacionais e drenagem de

3) Bairro Parque do Sol entre a confluência das ruas Urbano e Cantareira. águas pluviais deficitária (IPT, 2009). Acúmulo pontuais de resíduos de construção civil (RCC) e orgânicos dificultando a drenagem.

4) Bairro Parque do Sol entre a confluência das ruas $\quad$-Expansão dos núcleos habitacionais e drenagem de Urbano e Paraíso. $\quad$ águas pluviais deficitária (IPT, 2009).

Segundo a resolução CONAMA no 357/2005 as águas do córrego Oriente são do tipo classe 2 conforme enquadramento dos corpos de água pelo Decreto no 10755/1977 do Estado de São Paulo. Para as análises de água, somente a $\left(\mathrm{DBO}_{5}{ }^{20}\right)$ e $(\mathrm{OD})$ apresentaram valores significativos de alteração de acordo com a resolução CONAMA no 357/2005 que dispõe os (VMP) para este tipo de rio. $O$ ponto de coleta 1 (montante) recebeu contribuição das nascentes localizadas na área urbana e o ponto de coleta 2 (jusante) obteve colaboração das nascentes presentes na área rural da bacia. No trajeto do córrego, os valores de $\mathrm{DBO}_{5}{ }^{20}$ aumentaram de um ponto para o outro $3 \mathrm{mg} / \mathrm{l}$ no mês de maio e $2 \mathrm{mg} / \mathrm{l}$ em agosto. Os dados indicam que o rio recebeu cargas poluidoras de origem orgânica ao longo do seu curso e aumentando gradativamente até sua foz, no qual, houve queda na concentração de oxigênio de um local para o outro devido a autodepuração do corpo d'água. No mês de maio o ponto 2 ficou 1,43 mg/l abaixo do limite de $5 \mathrm{mg} / \mathrm{l}$ imposto pela resolução, no qual pode dificultar a sobrevivência da vida aquática.

\section{CONCLUSÃO}

O córrego Oriente apresentou um uso do solo urbano e rural. A expansão dos núcleos habitacionais decorreu nas áreas de cabeceira avançando no sentido sudeste da bacia. As áreas de pastagens, locais estes destinados para a criação de animais bovinos, representou a classe de ocupação predominante na área. Os parâmetros de qualidade da água que sofreram alteração, estão relacionados com o escoamento superficial da área urbana para o primeiro ponto de coleta, das áreas agrícolas e rurais para o segundo ponto. A combinação do uso urbano e rural associado a falta de vegetação intensificaram os fenômenos de assoreamento, erosão e acúmulo de matéria orgânica no rio.

\section{AGRADECIMENTO}

Pela bolsa de iniciação científica concedida mediante Conselho Nacional de Desenvolvimento Científico e Tecnológico (CNPq).

\section{REFERÊNCIAS}

ARAÚJO, Ronaldo de Sousa et al. Water resource management: A comparative evaluation of Brazil, Rio de Janeiro, the European Union, and Portugal. Science of the Total Environment, v.511, p.815-828, 2015.

AUTODESK. AUTOCAD. Software gratuito para utilização estudantil disponível para download por meio deste link: <https://www.autodesk.com.br/education/free-educational-software>. 
BRASIL. Lei no 9433, de 8 de janeiro de 1997 - Institui a política nacional de recursos hídricos, cria o sistema nacional de gerenciamento de recursos hídricos e dá outras providências. Planalto, Brasília. Disponível em: <http://www4.planalto.gov.br/legislacao>.

CEPAGRI - Centro de Pesquisas Meteorológicas e Climáticas Aplicadas a Agricultura. Clima dos municípios paulistas. Unicamp, Campinas. Disponível em: <https://www.cpa.unicamp.br>.

CONAMA - Conselho Nacional do Meio Ambiente. Resolução no 357, de 17 de março de 2005 - Dispõe sobre a classificação dos corpos de água e diretrizes ambientais para o seu enquadramento, bem como estabelece as condições e padrões de lançamento de efluentes e dá outras providências. Ministério do Meio Ambiente, Brasília. Disponível em: <http://www.mma.gov.br>.

CUNHA, Davi Gasparini Fernandes et al. Land use influence on raw water quality and treatment costs for drinking supply in São Paulo State (Brazil). Ecological Engineering, v.94, p.516-524, 2016.

EMBRAPA - Empresa Brasileira de Pesquisa Agropecuária. Imagem SRTM. Disponível para download por meio deste link: <http://www.relevobr.cnpm.embrapa.br/download/>.

GOOGLE. GOOGLE EARTH. Software gratuito disponível para download por meio deste link: <http://www.google.com.br/earth/download/ge/agree.html>.

GUERRA, Antônio José Teixeira; CUNHA, Sandra Baptista. Geomorfologia uma atualização de bases e conceitos. 7ed. Rio de janeiro. Bertrand Brasil, 2007.

INPE - Instituto Nacional de Pesquisas Espaciais. SPRING. Software gratuito disponível para download por meio deste link: <http://www.dpi.inpe.br/spring/>. Copyright (C) 1991-2018.

IPT - Instituto de Pesquisas Tecnológicas. Plano de macrodrenagem do município de Adamantina. Parecer técnico no 15713-301-1, São Paulo, 2009.

MENEZES, João Paulo Cunha et al. Relação entre padrões de uso e ocupação do solo e qualidade da água em uma bacia hidrográfica urbana. Engenharia Sanitária e Ambiental, v.21, n.03, p.519-534, 2016.

MENEZES, Michele Duarte et al. Dinâmica hidrológica de duas nascentes, associada ao uso do solo, características pedológicas e atributos físico-hídricos na sub-bacia hidrográfica do Ribeirão Lavrinha - Serra da Mantiqueira (MG). Scientia Forestalis, v.37, n.82, p.175-184, Piracicaba, 2009.

SÃO PAULO. Decreto no 10755, de 22 de novembro de 1977 - Dispõe sobre o enquadramento dos corpos de água receptores na classificação prevista no Decreto no 8468 , de 8 de setembro de 1976 e dá providências correlatas. Assembleia Legislativa do Estado de São Paulo, São Paulo. Disponível em: <https://www.al.sp.gov.br/norma/153028>. 
SETTI, Arnaldo Augusto et al. Introdução ao gerenciamento de recursos hídricos. Agência Nacional de Energia Elétrica, Superintendência de Estudos e Informações Hidrológicas, 2ạ. ed. Brasília, 2001. 207f.

SILVA, Roselir Ribeiro. Bacia do rio pomba (MG): uso e ocupação do solo e impactos ambientais nos recursos hídricos. Tese (Doutorado), Universidade Federal de Goiás. Goiânia, 2014. $135 f$.

SILVA, Cícero Ramos Pereira et al. Diferentes modelos digitais de elevação na caracterização física da bacia hidrográfica do Rio Nandico, MT, Brasil. Scientia Plena, v.11, n.05, p.1-11, 2015.

VANZELA, Luiz et al. Influência do uso e ocupação do solo nos recursos hídricos do Córrego Três Barras, Marinópolis. Revista Brasileira de Engenharia Agrícola e Ambiental. v.14, n.01, p.55-64, Campina Grande, 2010.

XAVIER, Christine da Fonseca. Avaliação da influência do uso e ocupação do solo e de características geomorfológicas sobre a qualidade das águas de dois reservatórios da região metropolitana de Curitiba - Paraná. Dissertação (Mestrado), Universidade Federal do Paraná. Curitiba, 2005. $167 f$. 